\title{
Brain Death as the End of a Human Organism as a Self-Moving Whole
}

Penultimate draft. Please cite the hard copy in JMP. Available at: https://doi.org/10.1093/jmp/jhab021 or request a copy from me: omelianchuk@gmail.com

\begin{abstract}
The biophilosophic justification for the idea that "brain death" (or total brain failure) is death needs to support two claims: (1) that what dies in human death is a human organism, not merely a psychological entity distinct from it; (2) that total brain failure signifies the end of the human organism as a whole. Defenders of brain death typically assume without argument the first claim is true and argue for the second by defending the "integrative unity" rationale. Yet the integrative unity rationale has fallen on hard times. In this paper, I give reasons for why we should think of ourselves as organisms, and why the "fundamental work" rationale put forward by the 2008 President's Council is better than the integrative unity rationale despite persistent objections to it.
\end{abstract}

We define death as the permanent cessation of functioning of the organism as a whole... The function of the organism as a whole means the spontaneous and innate activities carried out by the integration of all or most subsystems...

—Bernat, Culver, and Gert (1981)

I believe that the strongest justification for the brain death concept is not the integration rationale but the cessation of the organism as a whole.

—James Bernat (2014)

The change in the epigraph statements is no small one. In 1981, Bernat and colleagues emphasized the loss of a special kind of activity of an organism, specifically integrative unity, as signifying death; 33 years later, Bernat (sans colleagues) retracted this claim and asserted the loss of the organism itself is what matters. This assertion is deeply metaphysical because human death is linked to human organisms, not some special property of those organisms like "personhood," a property that is often analyzed in terms of mental or socially constructed properties (or both). Nor does it permit that there are such things as dead organisms, or at least a dead organism as a whole. It also raises a pressing question: what apart from an organism's activity indicates that an organism as a whole exists? It is hard to specify. If there is nothing else, then what sort of activity is indicative of organisms in general that ceases? Lastly, and most importantly, what is the justification for believing that the destruction of the brain is a sufficient for the cessation of the human organism as a whole? Before answering these questions, though, 
we might wonder if determining the death of human organisms is even the right place to start. Perhaps "our" death conditions differ from those of organisms in general, and "we" are not organisms at all.

The goal of this paper is to answer these questions and offer a defense of "brain death," or "total brain failure" as it is more accurately called (President's Council on Bioethics 2008), which takes seriously the issues of human ontology and human biology. ${ }^{1}$ It is often assumed without argument in the brain-death literature that we are organisms, except for some so-called "higher" brain advocates who argue that we are either some sort of psychological or social entity (or both) whose death can be identified by the loss of a certain form of neocortical brain activity linked to our capacity for consciousness or social interaction (Green and Wikler 1980; McMahan 2002; Lizza 2006; Veatch 1975; Gervais 1986). Common to these views is the assumption that one can "die" by ceasing to exist qua "person" while one's organism continues on. A contrary view is that we are organisms, alright, but our organism can survive the loss of functioning of the entire brain including the brain stem (e.g. Shewmon 2010; Miller and Truog 2012). My purpose is to rebut both of these views. In the first section, I argue that we have good metaphysical reasons to conceive of death as involving the end of a human organism as a self-moving whole — where wholeness is analyzed in terms of a basic, second-order capacity (viz. a capacity for having a capacity) for self-movement towards species-specific ends — rather than merely the loss of a special property of that whole, such as "personhood," or even the first-order capacity for self-movement (which can be lost in reversible cases of hypothermia or barbiturate overdoses). In the second, I address the influential argument of D. Alan Shewmon that neurological criteria

\footnotetext{
${ }^{1}$ I shall typically use "total brain failure" throughout the rest of this paper as it has been proposed by the 2008 President's Council and accepted even by D. Alan Shewmon, the leading critic of neurological criteria for death, as being a "philosophically neutral and physiologically clearer" term (Shewmon 2009b, 6). I will use "brain death" when it seems fitting as a matter of stylistic felicity but assume that it is synonymous with "total brain failure."
} 
are inadequate for determining death. In the third, I offer a fresh defense of the "fundamental work" criteria for wholeness as specified in "Position Two" of the President's Council's "White Paper" on the subject (President's Council on Bioethics 2008), and explain how self-movement towards species-specific ends relates to the "fundamental work" rationale it names in its definition of death, and the capacities for consciousness and respiratory effort in its diagnostic criteria.

One might reasonably wonder why another paper on this topic is worth writing. There are three reasons to revisit it. First, despite recent defenses of biological death as signified by total brain failure advanced in the literature, they do not address the fundamental questions surrounding human ontology and mostly try to rehabilitate the integrative unity rationale (e.g. Moschella 2016a, 2016b; Condic 2016). Second, the idea of "self-movement" and the order of capacities it can have are underappreciated in the literature, something our philosophy of organism and biology should pay more attention to. Third, the "fundamental work" criteria of the President's Council has not received much defense and has often been met with incredulity or dismissed as being ad hoc (e.g. Nair-Collins and Miller 2017). This paper seeks to remedy these issues by making better sense of the shift in Bernat's thinking on this topic over the last 35 years, which I take to be representative of a positive development in the theoretical justification for the idea that total brain failure is death.

\subsection{What dies in human death?}

A sound analysis of human death should begin with the question, "What are we?" If we get this question wrong or ignore it completely, then our determinations of death are inattentive to their object and perhaps overly conservative. This may not be a problem for medicine in general, since its purposes are not concerned with the fundamental objects of reality. 
Philosophically speaking, however, if the personhood views associated with the "higher" brain criteria are true, then continuing the debate over whether total brain failure is death is inappropriate (Gervais 2014). What are we, then? It seems easy to say, but it is not. Perhaps we are wholly material beings, or amalgams of body and soul, or an immaterial soul closely related to a body we somehow animate. ${ }^{2}$ Perhaps death is the end of us, or perhaps not; I will not be so bold as to rule out the possibility that we survive our death in some way and "go on" to the realm of the afterlife. What I will contend for, however, is a broadly "biological approach" to human ontology, which takes the normal condition of human life to be within the purview of the biological sciences. From the biological point of view, those of us who are living can at least be classified as organisms, a common enough observation, though lacking specificity concerning our metaphysical nature and how it informs the distinction between death and dying. Shewmon is right when he complains that our "philosophy of the organism" is currently underdeveloped and unable to furnish a bright line between injured organisms and non-organisms along a finelygrained spectrum of injuries (Shewmon 2010, 261). Nonetheless, the category of "organism" is sufficiently robust to begin a philosophical investigation into our nature, and it can be refined with a view towards answering Shewmon's claim that a human organism as a whole does not depend for its existence on a functioning brain.

\subsection{Addressing two objections to the organism view}

I shall begin by addressing two objections to the idea that we are organisms to better motivate what I take organisms to be. The first objection is against the idea that organisms are

\footnotetext{
${ }^{2}$ For those who are interested, I leave aside the view that we might be four-dimensional space-time worms made up of temporal parts, because I am not able to make sense of a temporal part. Either temporal parts have duration or they don't. If they do, then why do they need to be invoked at all? I could just as well be a single improper temporal part on a standard eternalist view of time. If they don't have duration $(=0)$, then how do they add up to anything temporally extended? Perhaps there is a simple answer here, but it is lost on me. I can only plead the informed reader's forgiveness.
} 
essentially living beings, an idea which is thought to be incompatible with our "commonsense" view of organisms. Jeff McMahan is right when he claims that it is a matter of commonsense to view an organism undergoing a "catastrophic change" when it dies a normal death, but he makes a more controversial claim when he asserts that (if the organism view is true) one changes from being a living organism to a dead one, i.e. we endure our death $(2002,30)$. This, he believes, is more acceptable than four other alternatives: (1) a brand new entity called "the corpse" comes into existence that exactly occupies the space previously occupied by the organism; (2) there was a corpse-like hunk of matter that spatially coincided with the organism before death whose persistence conditions apply after death whereas the organism's do not; (3) the property of being an organism is a phase of a more fundamental hunk of matter which ends at death; and finally (4) there is no such thing as "the corpse" that follows after death, just an unordered aggregate of particles. Yet despite being superior to these four alternatives, McMahan thinks it is hard to believe we could become dead organisms; he says, "unless one is a soul that bides awhile before fluttering away to its celestial abode, one will no longer be present when one's organism becomes a corpse" (Ibid.). Thus, we have no reason to believe we are organisms.

While McMahan does not think this is a decisive argument, it does motivate his braintransplant thought-experiment, which leads him to identify us with part of the brain that has a capacity for consciousness and our death is determined by "higher" brain criteria. ${ }^{3}$ Those

\footnotetext{
${ }^{3}$ On the brain transplant thought-experiment: the idea is that if surgeons removed your cerebrum and placed it in the skull of your cerebrum-less identical twin, you would go with your cerebrum. I do not find this to be compelling, because the psychological connectedness we have with our cerebrums is not sufficient for our persistence over time. If it were, then there would be two of us if each of our cerebral hemispheres were transplanted into different heads, which is absurd: one thing cannot be identical with two different things. To his credit McMahan acknowledges this, and follows Parfit in the claim that the survival of our qualitative psychological properties is what matters, not our identity (McMahan 2002, 43; Parfit 1984, chap. 12). I leave it to the reader to decide whether this increases the plausibility of his proposal under his assumption that commonsense intuition is to guide our evaluation of these views.
} 
unwilling to follow him on this point should address his criticisms of the organism view. ${ }^{4}$ Do we survive death for a while as a corpse and then go out of existence at some stage of decomposition? I find this harder to believe than the view that eliminates corpses from our ontology, because it is very hard to believe that corpses are genuine wholes that amount to something more than just the sum of their (decomposing) parts. Nor should those who want to retain corpses on the list of real things in the world be bothered by the idea of a corpse coming into existence after the death of an organism, because the persistence conditions of corpses and organisms are incompatible. No organism can survive decomposition, alright, but if organisms can survive death, why should they not be able to survive decomposition? There seems to be no fundamental difference between decomposition and death, insofar as death is the onset of decomposition marked by a loss of entropy-resistant metabolism (Schrödinger 1992, chap. 6). Hence, the plausible view that an organism survives only if its metabolic processes continue without interruption such that new particles are configured and assimilated into its complex organic structure, and old ones no longer useful to the structure are jettisoned as waste (Blatti 2014; Olson 1997, 16; 2007, 28). ${ }^{5}$ As Eric Olson explains:

A corpse, like a marble statue, maintains its form merely by virtue of the intrinsic stability of its materials. The stability of a living thing, by contrast, is dynamic. Matter constantly flows through it, in much the same way as it flows through a fountain. A living thing maintains its form - in particular the fine biochemical structure that makes it alive - only by engaging in constant activity: repairing damage, removing waste, fighting infection, acquiring and digesting food, and so on. All of this comes to an end when the organism dies. Matter ceases to flow. The repairs stop. Decay sets in. It is this irreversible process that we call death. If ending an organism's life appears less dramatic than shutting off a fountain, that is because some of an organism's materials - its solid parts - are more stable than those of a fountain. But even its solid parts 'flow' $(2004,269)$.

\footnotetext{
${ }^{4}$ His arguments are at least taken seriously by LiPuma and DeMarco (2014).

5 This is also thought to be a sufficient condition for organisms to exist, but I deny this for reasons below.
} 
Since this dynamic activity is characteristic of organisms, there is no reason why the organism cannot incorporate some relevant set of particles into itself as being caught up in the life of the organism, nor is there any reason to think it odd if members of that set continue to persist when that life is finished. ${ }^{6}$ Once this entropy-resisting process ceases there is no more organism. Hence, a dead organism is just an organism "in name only" as Aristotle would say.

The second objection against the claim that we can be classified as organisms comes from an appeal to the phenomenon of dicephalic twinning (Campbell and McMahan 2010; McMahan 2002, 35-39). Consider Brittany and Abigail Hensel, two women whose heads extend from a single, four-limbed body that houses two hearts, two stomachs, two gallbladders, four lungs, three kidneys, a single diaphragm, a liver, a large intestine, and a set of reproductive organs. ${ }^{7}$ They share a common blood stream and immune system; yet each twin has her own nervous system which senses and controls her own side of the body. As such, they appear to be two individuals caught up in the life of a single human organism; therefore, Brittany and Abigail cannot be classified as organisms, and since they are not fundamentally different from us, neither can we.

The argument from dicephalic twinning is usually marshalled against the view that we are identical with organisms, which entails that we are essentially organisms. That is not something I assume here, but never mind. The relevant question the argument raises is how organisms are individuated, an ongoing issue in the philosophy of biology (e.g. Bouchard and Huneman 2013). As I see it, there is no decisive reason to believe there is exactly one organism

\footnotetext{
${ }^{6}$ Owen Flanagan estimates that one who lives seventy years could have up to ten different completely replaced sets of cells that compose one's body, or in his words "ten different bodies in a lifetime" $(1991,17)$. Whether these bodies spatially coincide with the organism will depend on our metaphysics of composition or substance.

${ }^{7}$ I once saw Brittany and Abigail playing frisbee at Bethel University circa 2008-2009. It's hard to describe how awe-inspiring that was.
} 
where Brittany and Abigail are, and some good reasons to believe there are two which share some of the same space with one another. First, if there is exactly one human organism where the Hensel twins are, then it is not clear how the organs within the twins are biologically related to them. Lee and George state the problem nicely:

Each set of eyes, each set of ears, and so on would not belong biologically more to one girl than the other. Each of these organs would have to be a part of a single larger organism, subservient to the survival and function of this one organism. But this plainly is not the case. It is indisputable that each one biologically has not only her own brain, but also her own skull, eyes, ears, and many organs, while sharing many other organs (2008, 47 emphasis original).

Campbell and McMahan are eager to agree that some of the organs, to use their words, "serve only one of the two persons" $(2010,291)$. But in virtue of what, if not a numerically distinct organism, do they do this? They claim that, "one sibling's eyes 'belong' to her because they are the ones that she sees with. That is exactly what one would expect when two persons are sustained by a single organism" (Ibid, 291 emphasis original). The point appears to be that an organ 'belongs' to a person by virtue of the fact that the person uses and benefits from the function of the organ in question and no one else does. But this cannot be right. If it were, then the kidneys of the person kidnapped by the Society of Music Lovers in Judith Jarvis Thomson's famous thought experiment would no longer 'belong' to the person, because, after all, they are now being used by the sickly violinist to filter toxins from his blood (Thomson 1971, 48-49). This functional activity is shared between the violinist and the kidnapped person no less than it is for the Hensel twins. But clearly the kidneys belong to the kidnapped person rather than the violinist. This is because the kidneys, along with every other organ in the kidnapped person's body are integrated into the life of the organism by virtue of the organism's coordinating activity for the sake of the organism's survival. In the case of the Hensel twins, there is overlapping 
integration when it comes to their kidneys, but there is no overlap when it comes to their sense organs. Hence, Brittany's eyes do not belong to Abigail (and vice versa), because they are not integrated into the coordinating activity of her organism.

Second, the fact that each twin develops not only her own head complete with a full set of sensory organs, but also her own spine and nervous system that senses and controls one side of the body — as well as her own heart, stomach, esophagus, and pair of lungs — indicates the presence of two distinct, though not completely independent entities. What else could those entities be besides numerically distinct human organisms? This hypothesis fits well with the facts of human embryology since dicephalic twinning occurs when the fission-process of monozygotic twinning fails to completely separate the two embryos from one another (Kaufman 2004). It is not some genetic or epigenetic condition of a single embryonic organism. Why should we, then, count only one human organism in this case and not two? Perhaps the reason is that we assume that two human organisms cannot share some of the same physical space. We should not assume that, however, unless we are willing to suppose that, for any case of conjoined twinning no matter how trivial (say they are joined at the pinky toe), two brand new organisms would suddenly pop into existence if the twins were surgically separated. Thus, it is more plausible to believe that two teleological centers of life conjoin and develop together within a shared space wherein two distinct capacities for directing and regulating life-processes can be identified and that is all that is needed to say there are two organisms there (Liao 2006, 340-41).

Before making a positive case for thinking of ourselves as organisms, let me pause for a moment to say that I will not be surprised if advocates of the "higher" brain view remain skeptical of these arguments. The ontology of human persons is notoriously difficult and is of limited use in guiding our policies in the hospital room. But even if our metaphysical disputes 
are judged to be indeterminate, then, on the basis of the precautionary principle, the best epistemic position that we can be in when determining the irreversible loss of whatever psychological or social property is thought to be essential to us is one that satisfies the accepted neurological criteria. Given that the criteria for total brain failure are our most demanding neurological criteria, we can have a high degree of certainty that no human person remains after they are satisfied. The same principle also applies to declaring death on the basis of circulatory criteria: no one should be declared dead by circulatory criteria if we do not know for sure that someone has irreversibly lost their capacity for consciousness (Napier 2011). Thus, even if the organism view turns out to be false, nothing significant should change insofar as our deathdeclaring policies go. All I have tried to show here is that there are good reasons for thinking the case against the organism view fails.

\subsection{In favor of the organism view}

What positive arguments are there for thinking of ourselves as organisms? Part of the problem with answering this question concerns what we take organisms to be. As a philosophic category, organisms should not be construed as being in the domain of one side in the divide between materialists and non-materialists, though it can certainly seem that way. Those who defend a biological approach to personal identity (a topic which should not be confused with human ontology) often use the term "organism" interchangeably with the word "animal" within a materialistic framework (e.g. Olson 1997; 2015). By contrast immaterialists like Descartes take an impersonal, and implausible, "machine" view of organisms (which is aptly criticized by Nicholson 2013; 2014). A better understanding of organisms is one that places them in the category of substance, a category materialists like Peter van Inwagen (1990; 2007, 200), hylomorphists like Patrick Toner (2011), and even dualists like Richard Swinburne (1997, 153) 
use when articulating their accounts in terms of their vastly different ontologies. As substances, organisms are concrete particulars that endure through time, survive change, derive their unity from their internal structure or essence, possess causal powers not reducible to their parts, and are wholes that are ontologically prior to their parts such that the parts receive their identity by virtue of their place in whole. ${ }^{8}$ Is there any argument for believing we are this sort of thing?

Here is a question worth asking: do we bear the capacity for biological human life? More specifically, is there a substance with which we can be identified that (1) bears the capacity for developing and functioning in the form of a human organism, resisting the forces of entropy from the moment of conception or twining (or implantation ${ }^{9}$ ) onward, and that (2) subsequently loses this capacity in death? If there is, then we can live the lives of human organisms and survive the loss of consciousness. Whether this substance can survive death in the form of something else is a question I shall leave aside. ${ }^{10} \mathrm{~A}$ sound answer to that question will depend on whether we have the capacity to survive death, which is independent of the question I ask here: do we have the capacity to live a biological human life? If not, then either our biological human lives derive from something that does, or we are not the sort of the thing to which biological life applies at all.

Suppose we are not the sort of thing to which biological life applies at all. Then our fundamental nature is entirely outside the purview of biology. We share nothing in common with the natural history of living things on our planet and we quite literally do not need food, water, or air to survive. That we depend on organisms to get around and do the stuff we do is just a funny

\footnotetext{
${ }^{8} \mathrm{My}$ view is at home in the Aristotelian tradition and is ably defended in contemporary form by David Braine (Braine 1992, 256-67) and J.P. Moreland (Moreland and Rae 2000, chap. 2), both of whom have had a deep influence on my thinking.

${ }^{9}$ See Smith and Brogaard (2003) for a defense of the implantation view; see George and Tollefsen (2008, chap. 2) for a defense of a conception/twinning view.

${ }^{10}$ I assume that being able to classify ourselves as organisms does not depend on our being identical with them. For a view that classifies us as organisms, but identifies us with "embodied souls" see Gilbert Meilaender (1993).
} 
contingent fact about our universe. But we really do not need these mangy creatures to get by any more than we need a car to get from Mobile to Milwaukee. Medical tests for death, then, relate to organisms insofar as we depend on them for our functioning. These tests will likely zero in on our organism's higher-brain functions, the functions upon which we happen to depend for being recognizable in this world. Yet it is very hard to understand what we could be on this view. All we know is that we can do stuff, though we are not strictly speaking biologically alive. Are we a kind of computer program that can be "uploaded" and "downloaded" if need be (e.g. Dennett 1978)? Then we are just bits of information, a kind of universal that is timelessly eternal and bereft of causal powers, which is contrary to our assumption that we can act and do things. If we are some sort of immaterial soul, then we need some reason to believe that, in spite of having the relevant capacities to interact with the material world so as to act and do things, we do not have the relevant capacities to interact with the material world so as to live a biological human life. There is simply no reason why, on any principled view of substance dualism, that this should be the case.

What about the idea that our biological human life derives from something else that bears the capacity for it? This is a more interesting suggestion, because it makes use of the category of derivative properties. ${ }^{11}$ For instance, a race horse crosses the finish line in a secondary, derivative sense because its nose crossed the line in a primary, non-derivative sense. In this case, the parthood relation allows us to make an appropriate derivation of the relevant property (Swinburne 1997, 145). Likewise, if we are part of a brain, we are biologically alive in a derivative sense, because the organism of which we are a part is alive in the non-derivative sense (McMahan 2002, 88-94). The same goes for "persons" who are materially constituted by an

\footnotetext{
${ }^{11}$ Here I am indebted by Andrew M. Bailey (2016). What follows is a summary of his argument.
} 
organism (Baker 2000, 99). In each case, there is an appropriate relation between us and our organism, which allows us to attribute the properties of the organism to ourselves by way of some rule of derivation. ${ }^{12}$ We get infected if our organism gets infected, we get punched if our organism gets punched, and so on. Derivative properties abound, and sometimes they go the other way: that a human organism thinks is derived from the fact that we think. In this way, I can consistently think of myself as bearing the capacity for biological human life in the derivative sense. If this is the case, then I am a human organism in the derivative sense. But consider this argument (adapted from Bailey 2016, 207-8):

1. I am a human organism in either the derivative sense, or the non-derivative sense.

2. If I am a human organism in the derivative sense, then there are two human organisms in my immediate vicinity.

3. But there is only one human organism in my immediate vicinity.

4. Therefore, I am not a human organism in the derivative sense $(2,3)$

5. Therefore, I am a human organism in the non-derivative sense $(1,4)$.

To deny premise [1] is to opt for the claim we are not the sort of thing to which biological life applies, which is a claim we have already examined and found wanting. Premise [2] rests on the plausible assumption that something exists if something has a property; since two things end up having the property of being a human organism — me and the organism — there are two human organisms in the neighborhood. Premise [3] is hard to deny; all we have to do is inspect the immediate vicinity where I am and start counting: "one" is as far as we are going to get. ${ }^{13}$

A final objection to this argument would be to deny the initial claim that bearing the capacity for living a biological human life is sufficient for being a human organism. One could

\footnotetext{
12 Bailey notes that these are rarely, if ever, formally articulated. Speaking in defense of her "constitution view" Baker gives a nice example: "Roughly, (omitting reference to times), $\mathrm{x}$ has F nonderivatively iff x's having $\mathrm{F}$ does not depend on x's constitution relations, and $\mathrm{x}$ has $\mathrm{F}$ derivatively iff $\mathrm{x}$ 's having $\mathrm{F}$ depends on $\mathrm{x}$ 's having constitution relations with something that has F nonderivatively" (Baker 2008, 43).

${ }^{13}$ It is worth mentioning that if we count two, we end up violating McMahan's plausible assumption that "there can be no more than one of a particular kind at a given place at a given time" $(2002,90)$. Perhaps this not a problem for everyone, but it is for McMahan, a point I owe to David Hershenov $(2005,33)$.
} 
argue that a pair of human gametes or any of our somatic cells have this capacity, but neither of these is a human organism like us (Singer and Dawson 1988; Charo 2001). Yet it is hard to understand how a pair of gametes, which only composes a mereological sum and not a genuinely unified whole, bears such a capacity. Since neither of them individually bears the capacity for living a biological human life, no new human organism will ever come to be if they never meet. Same goes for our somatic cells: leave them to do what they normally do, and no human organism will result. The fact that these things can stand in a causal relationship to a new human organism is not sufficient for them to bear the capacity for living a biological human life. To think otherwise is to stumble over an ambiguity that fails to capture the sort of capacity I have in mind: a capacity that is exercisable by the entity that has it. This sort of capacity is a power within the entity to produce change within itself, and since this change presupposes the sameness of the entity that produces it, this capacity is "identity-preserving." Neither the pair of gametes, nor any of our somatic cells have this sort of capacity. Rather, they only have a "compositional capacity" which requires that they be acted upon by an external agent to effect the desired change - a change they do not survive - so that something new can come to be (See DiSilvestro 2010, 108:18-19 for a nice overview of these distinctions.). Since this new entity, which comes to be in the form of a human embryo, bears an active, identity-preserving capacity to live a biological human life, it is as good a candidate as any to be a human organism.

Therefore, we have good reason to believe we die when a human organism dies, because when that occurs, we lose our capacity to live a biological human life.

\subsection{On determining death in human organisms}

Unfortunately, determining the death of a human organism faces its own set of deep and hard metaphysical and epistemological questions. Specifically, what is needed is some mark by 
which we can empirically determine that the life of a human organism is finished. Given that an organism survives only if an organism's entropy-resisting metabolic processes continue without interruption, the mark should be related to when these cease. Thus, we should agree with Miller and Truog when they assert that "death occurs at the moment when the entropy-increasing forces have irreversibly exceeded those that are resisting this process" $(2012,70)$. Normally, what follows this event is the beginning of the process of decay. Death, then, is thought to be marked by the "disintegration" of the organism as a whole, and, conversely, life is thought to be marked by the "integration" of the organism as a whole (President's Commission for the Study of Ethical Problems in Medicine and Biomedical and Behavioral Research 1981, 33, 77). Hence, the intuitive plausibility of the "integrative unity" model of life and death. Organ transplantation well illustrates this enduring idea that goes back to Aristotle: just as a severed hand is a hand in name only, so too is a severed heart, lung, liver, or kidney unless it is promptly reattached. If it is reattached to someone genetically distinct from the donor, immunosuppression treatment is usually needed so that the host will not reject the foreign organ and fail to integrate it into its lifesustaining work.

\subsection{Shewmon's challenge to the "integrative unity" model}

Just what the source of this "integrative unity" is, however, is a contentious question. As far as I can tell, the debate has been framed by the assumption that only organisms are able to exemplify integrative unity. For better or worse, then, the dispute over whether total brain failure is equivalent with death has traditionally been a dispute over whether the brain is necessary for the integration of the organism as a whole. An influential interpretation of death canonized in the paper by Bernat, Culver, and Gert (1981) is that the brain is the principal source of integration the "integrator" of the human organism, so to speak. Thus, in their description of various deaths, 
whether by hanging, chronic disease, or massive head injury, death always coincides with a total loss of brain function, which brings about disintegration (Ibid., 392-93). This idea was challenged in a deep and compelling way in a series of papers by D. Alan Shewmon (1997; $1998 ; 2001)$, who persuasively argued that the source of this integration is not localizable in any one organ. While he agreed that the brain substantially contributes to the integration of the organism as a whole, he disagreed that it confers integration on the organism as a whole. If he is right, then it seems that the brain-dead body can survive as an organism so long as its integrative unity remains intact.

It is worth examining the operational definition Shewmon gives of "integrative unity" and his criteria for determining whether it is present. Within the orthodox biological paradigm, he thinks integrative unity should be:

1. Applicable to all living organisms.

2. Reflective of the thermodynamic characteristic of life being anti-entropic.

3. Absent in corpses.

4. Internally holistic, which distinguishes organisms as wholes, rather than a mere collection of organs, tissues, and cells which require some external force to artificially unify them.

5. An all-or-nothing, non-degreed property that is either present or absent.

6. Compatible with profound disability or moribund status.

7. Compatible with being irreversibly unconscious.

Hence, Shewmon says a putative organism possesses "integrative unity" when it "possesses at least one emergent, holistic-level property" (2001, 461 emphasis orginal). A paradigm example is consciousness. In Shewmon's view, an isolated, yet conscious brain is an organism as a whole, though, of course not a whole organism (Ibid., 461). ${ }^{14}$ Other examples of emergent holistic-level properties include homeostasis, elimination of waste, energy balance, regulation of temperature, wound healing, infection fighting, fetal gestation, sexual maturation

\footnotetext{
14 This position was subsequently denied by Shewmon eight years later (2009a), but then reaffirmed three years after this denial (2012). I believe his uncertainty is explained by the permissiveness of his criteria, something I contend for below.
} 
through puberty, proportional growth, and electrolyte balance - all things he has found in subjects diagnosed with total brain failure (Ibid., 467-68). He even asserts that respiration and nutrition are characteristic of an integrative unity that does not depend upon the brain. By "respiration" he means the biochemical process by which oxygen and carbon dioxide transfer "across the alveolar lining of the lungs" or "the electron transport chain in the mitochondria of every cell in the body" (Ibid., 464). By "nutrition" he means "the breakdown of food into elemental forms that are either biochemically burned for energy or assimilated into the body's structure" (Ibid., 465). Since the brain has nothing do with these integrative functions, the absence of brain-function cannot signify an absence of integrative functioning in a human organism.

\subsection{Two living things, not one: A response to Shewmon}

What should we make of Shewmon's penetrating and searching criticisms of determining death on the basis of total brain failure? I suggest that the presence of integrative unity, as Shewmon defines it, is not sufficient for determining whether the entity that exemplifies it after total brain failure is identical with the entity before total brain failure. Indeed, I argue that something other than a human organism as a whole can exemplify Shewmon's idea of integrative unity. At first glance, this is a counter-intuitive claim. Nonetheless, I think it is plausible to construe total brain failure as a sign of discontinuity between an organism as a whole, and either a living part of an organism (albeit one that is rather large), or an "organism" in name only. To maintain continuity, Shewmon's operational criterion for integrative unity needs to be permissive enough to ensure that the brain-dead body remains a human organism as whole. Unfortunately, this permissiveness yields individuals that violate the transitivity of identity. ${ }^{15} \mathrm{We}$ have already

\footnotetext{
15 The following is influenced by Olson (2016) who responds to Shewmon's findings.
} 
seen that he allows for an isolated, yet conscious brain to be an organism as a whole; but what about the body from which it is removed? Suppose we maintain the brainless body and it exhibits all the life-signs that Shewmon lists as being present in brain-dead bodies. By Shewmon's criterion, then, the brainless body either "is a mutilated 'organism as a whole' or is a nonorganism with the metaphysical status of a severed limb" (Shewmon 2007, 304). Whatever they may be, both cannot be the same organism simply because one thing cannot be numerically identical with two things, since they differ in their properties (one is in a vat, the other is not). ${ }^{16}$ Either we go with the brain, the brainless body, or neither and that is the end of us. ${ }^{17}$ To his credit, Shewmon is aware of this implication, but he rejects the validity of fission-style thought experiments, because in the context of clinical diagnosis he says, "there is only one piece of living matter and only one person at issue" $(2010,263)$. What he means by this is not entirely clear, but whether one and the same entity survives total brain failure is precisely under dispute, so Shewmon cannot use this claim as a premise in an argument for the conclusion that the braindead body in the hospital bed is numerically identical with the organism before brain-death.

The permissiveness of Shewmon's criterion also transforms individual organs removed from the body and sustained by artificial means into individual organisms (Khushf 2010, 353). Suppose we remove a kidney, yet keep it "alive" in some sterile environment by perfusing it with

\footnotetext{
${ }^{16} \mathrm{I}$ assume there is no trans-spatial relation between the isolated brain and the brainless body, because such an occult relation is not only unacceptably ad hoc, it is also outside the purview of biology in general. As Khushf says, "If an account of death implies that the previous organism is sustained in both parts, so I could 'turn off' either part without causing the death of the original organism, then this only shows that Shewmon did not get the correct biological concept" $(2010,353)$. Thus, I assume that spatial contiguity is required by a sound theory of integrative unity.

${ }^{17}$ Failure to understand this point besets Miller and Truog's discussion of what they call "the decapitation gambit" and the status of a decapitated chicken that runs around aimlessly for a few moments $(2012,82 ; 2009 \mathrm{~b}$, 398). Supposing that it is alive, it does not follow that the headless chicken is identical with the chicken before decapitation. Thus, they miss the point of the division scenarios put forward by Lizza (2009a, 394) and Khushf (Khushf 2010, 352-53): the issue is not whether the brainless body is alive or an organism of some sort, but whether the brainless entity is numerically the same as the one with the brain.
} 
oxygenated blood from someone with renal failure. Then, by virtue of the fact that it respires oxygen and carbon dioxide, exchanges nutrients, and creates urine, it displays "integrative functioning" and is therefore an organism. But it isn't — it's just a detached organ that is neither continuous with the organism it came from, nor the one it is hooked up to. ${ }^{18}$ Why should we think that a brainless or headless body is any different?

Shewmon recognizes this sort of objection and responds with a what I take to be his best argument against it:

1. A functionally brain-disconnected patient on a ventilator (e.g. one suffering from a high spinal cord transection) is a severely disabled organism as a whole, not just a conscious head connected to an unintegrated collection of organs and tissues enclosed in a bag of skin.

2. The somatic effects of brain nonfunction are necessarily identical to those of brain disconnection.

3. Therefore, a patient without brain function is also a severely disabled organism as a whole (merely an unconscious one) $(2010,259)$.

As stated, the argument is formally invalid (Moschella 2016b, 281). Clearing away the otiose language it just says [1] The brain-disconnected patient is an organism as a whole; [2] the somatic effects below the point of disconnection are exactly similar to those found in a braindead patient; [3] therefore, the brain-dead patient is an organism as a whole. The premises can be true, and the conclusion false. My preferred way to make it valid goes like so:

1. The brain-disconnected patient is an organism as a whole.

2. There is no fundamental difference between the brain-disconnected patient and the braindead patient because both are exactly similar in terms of their somatic functioning below the injury.

3. Therefore, the brain-dead patient is an organism as a whole.

The problem with this argument is that the "somatic effects" mentioned in his second premise ("somatic functioning" in mine) are assumed to be sufficient for wholeness, but they are not

\footnotetext{
${ }^{18}$ In a later article, Shewmon came to agree with this, because the kidney only has the "structural" and "vitaloperational" wholeness of an organ, not an organism $(2012,433)$. We should ask however, why this same analysis cannot be applied to the brain-dead body?
} 
since they are beset by the "permissiveness" problem mentioned above: they permit artificially sustained organs to be classified as organisms. ${ }^{19}$ "Integrative unity" is not enough. Moreover, there is something deeper assumed in the first premise that makes it the case that the individual with the spinal cord transection is a unified whole. What could that be? It seems to me that what remains is a capacity for self-directedness or self-movement towards the distinctively human end of rational thought and action. It is this capacity that makes us "rational animals" - to use Aristotle's words again — and which (partly) distinguishes us from other species. ${ }^{20}$ Evidence for the presence of this capacity in transected individuals is found in the fact that they are conscious, complete with a drive to breath as signaled by the work of their brain stems, and the fact that their circulatory systems pump one quarter of their blood every minute to their brains: "Thought," as Henry Marsh remarks, "is an energy-intensive process" $(2014,41)$. This is not the case with headless bodies or brain dead bodies as illustrated by the infamous case of "TK" - a subject examined by Shewmon whose body persisted for twenty years after being diagnosed with total brain failure at age four (Shewmon 1998). At age eighteen, an MRI revealed no intracranial blood flow and the subsequent autopsy revealed a hardened spherical structure in place of the brain that had shrunken and calcified and lost all neuronal function (Repertinger et al. 2006). Still TK's body was living in some sense. This is hard to deny given the level of integrative functioning that was present in his body; indeed, it just sounds wrong to speak of TK as a "living cadaver," or a "warm-bodied corpse," or worst of all "a heart-lung preparation." That sort of language is inappropriate, if not absurd, and medical professionals would do well to

${ }^{19}$ As already cited, see Khushf's discussion (Khushf 2010, 353) as well as Robert Veatch's discussion of “A properly perfused, amputated limb" able to carry out certain growth and wound healing functions (Veatch 2015, 307). The point is that integrative somatic functioning is not sufficient for wholeness.

${ }^{20}$ There is some debate about whether dolphins or chimpanzees are classifiable as such, which is why I say "partly" in the parentheses, but I leave this aside. 
discard it. The assumption that there could not be a category of biological life that makes sense of "living remains" or "humanoids" or "biological remnants" is unwarranted. ${ }^{21}$ We could continue to follow Aristotle and nominalize these life-like objects as organisms "in name only" and retain our assumption that life can only be attributed to organisms. ${ }^{22}$ Or we could follow the project of Gary Rosenkrantz and recognize a third category when he says:

[M]ulti-cellular living organisms have other living things as proper parts, for instance, lung cells, sperm cells, nerve cells, and the like. However, living things of the latter sorts are insufficiently autonomous to qualify as full-fledged living organisms. That is, they are generally unable to survive for long apart from multi-cellular organisms under naturally obtaining conditions. On the other hand, some living entities of this sort can survive and reproduce apart from an organism under artificial conditions, for instance, in a tissue culture. The distinction between a living organism and such a living possible part (LPP) appears to be real, unconventional, and based upon the natural evolutionary causal priority of a living organism to a LPP (Rosenkrantz 2015, 307 emphasis orginal).

In any case, it is coherent to believe that there could be two "deaths" that occur in the hospital bed: the death of an organism as a whole (the human being), and the death of the living remains (the organism "in name only"). ${ }^{23}$ This would just be the logical consequence of an argument showing that the entity before total brain failure is not identical with the one that exists after total brain failure by virtue of a loss of wholeness. The relevant question, then, is whether there is such an argument.

With all the evidence to the contrary, I think there are some good reasons to think of a brain-dead body, as being a human organism "in name only" but not a real human organism. Thus, we need to think harder about what it means for a human organism to be an organism as a whole. Shewmon and other critics (e.g. Lizza 2018) are right to highlight the ambiguity of this

\footnotetext{
${ }^{21}$ Such an assumption is made by McMahan when he says, "Those who hold that brain death is death are obliged to describe the examples cited above as cases in which corpses support fetal gestation, maintain immune functions and adjust them to the presence of a fetus, metabolize nutrients, excrete wastes, retain reproductive potential, and so on" (2009, 289 emphasis original). Those who hold that brain death is death are not so obliged.

22 Thanks to an anonymous reviewer for pointing this out.

23 This effectively neutralizes the inconsistency Shewmon alleges against those who speak of brain-dead bodies as "dying" (Shewmon 2007, 297-98).
} 
idea. What exactly does this mean? The standard view is that the "organism as a whole" refers to something more than the sum of its parts by virtue of instantiating certain "emergent" properties that are not reducible to any of its parts (Bernat 2014, 5). This, I think, is too thin of an analysis. It is precisely this appeal to "emergence" that generates the ontological permissiveness in Shewmon's work and compels him to see the brain-dead body as being an organism as a whole. The problem is this: being an "emergent" property is one that is compatible with being supervenient on, or "over and above," some combination of subvenient parts that are metaphysically prior to the whole. Yet we need (and should) not think of organisms this way. Assuming organisms are substances, the whole is metaphysically prior to the parts, and the parts receive their "parthood" by virtue of being unified in the appropriate way by the activity of the whole. What we have said about the capacities of the individual with a transected spinal cord offers a clue as to what I am on about. An organism as a whole is an enduring, self-directed and self-moving entity in which its parts derive their identity and function from its internal structure, and it develops by virtue of its own capacities and powers latent in itself according to an information-rich design plan intrinsic to its kind towards a distinctive end or goal.

Death, then, is the end of the organism as a self-moving whole, meaning there is no more entity that has this active internal structure by which its parts receive their identity and function, no more development or activity toward a kind-distinctive end by virtue of its own capacities and powers. Just as this sort of entity does not persist after decapitation, neither does it persist after total brain failure. A mad neurosurgeon would not do anything fundamentally different to you than a medieval executioner if he were to empty the contents of your skull — it is not as if he is merely injuring you, albeit in a severe way. ${ }^{24}$ Rather, he is like the utilitarian transplant surgeon

\footnotetext{
${ }^{24}$ Doyen Nguyen poses an objection to my understanding of the analogy between brain death and decapitation (Nguyen 2018, 78). She argues that the physiology of brain death involves neither the division of the body into two
} 
who kills you by cutting you up and removing your heart and lungs without replacing them or supplementing their vital functions. The possibility of artificially sustaining a severed human head (a gruesome thought) raises the interesting question as to whether the severed head could remain a human organism as a whole. Settling this question matters not for my purpose, however, which is to argue that the headless body is not a human organism as a whole even if it is artificially maintained. Just as a headless body is not a human organism as a whole, neither is a brainless, severed head (assuming both are on life-support - an even more gruesome thought). Both are parts of a human organism, alright, but not human organisms themselves. Likewise, there is no more reason to believe something changes ontologically if the brainless head is attached, as if their connectedness is what makes all the difference between there being an organism as a whole there or not. Thus, if the brain totally fails through some accident or disease (like TK's), why should we not also think that a human organism as a whole ceases to be even if mechanical ventilation continues? ${ }^{25}$ We need not presume any dubious brain-body dualism that identifies the "us" with the brain to know that the basic capacity for an immanent, holistic, and teleological power of self-movement directed towards rational thought and action is lost in total

\footnotetext{
different parts, nor the severing of just the brain from the body, "but of the head with all of its associated anatomical structures including its arteries and veins," and therefore the cause of death results from massive blood loss rather than total brain failure (Ibid. n229). What this objection misses, however, is that the loss of something deeper can be caused either by massive blood loss or total brain failure: the basic capacity for self-movement towards the unified species-specific ends of rational thought and action, something I will explain more about below.

${ }^{25}$ In a recent article, Miller and Nair-Collins object to idea that brain-dead bodies only "appear to be alive" because the cause of their vital activity comes from a ventilator (Nair-Collins and Miller 2017). What they fail to consider, however, is what exactly it is that is being kept alive by the medical technology, an organism as a whole, or a very large part of an organism, something aptly noted by Moschella (2017) in her reply to their argument. The absence of a robust philosophy of an organism besets their entire analysis, which makes it unsurprising that they think that the "fundamental work" criterion invoked by the President's Council is "ad hoc" lacking an independent justification (Nair-Collins and Miller 2017, 751). On the contrary, such a criterion can be independently justified on Aristotelian grounds. In a more recent article, Nair-Collins evaluates the plausibility of the Aristotelian view and finds it wanting in terms of its competition with a modern, scientific view of the world (Nair-Collins 2018). Whatever this "scientific view" amounts to and whether it must be incompatible with Aristotelian metaphysics is not important for my response to his argument, which is just to assert that inattention to the identity conditions of individuals that exemplify homeostasis (his principle sign of life) persists.
} 
brain failure, just as it would be lost in the total stoppage of circulation in a case of

cardiopulmonary failure. By contrast, this immanent power is not lost in the ventilator-dependent patient with a spinal cord transection, the PVS patient, or the anencephalic baby. Everything in their bodies is continuously formed out of what Aristotle would call, "the source of its own production" (Phys. II 1.25-30, 192b), and while they may be injured or disabled in severe ways, they continue to be ordered towards their fundamental work as organisms: animal life with a conscious experience characterized by rational action. ${ }^{26}$

\subsection{An organism's "fundamental work"}

This talk of an organism's "fundamental work" comes from the President's Council on Bioethics lucidly written "White Paper," which functions partly as a response to Shewmon's discontent with "the integrative unity" rationale for "whole-brain death" as death (President's Council on Bioethics 2008). As they surveyed the issues of the brain-death debate, the members of the President's Council found it prudent to substitute the language of "whole-brain death" with the language of "total brain failure" so as to better reference the clinical condition that underlies the neurological test for death. In the position the members outline for the sake of justifying the neurological criterion (called Position Two), they reject the integrative unity rationale as being sufficient for the human organism's wholeness, and replaced it with a "fundamental work" rationale. ${ }^{27}$ The Council explains:

\footnotetext{
${ }^{26}$ One might fairly wonder how a PVS patient or an anencephalic baby could possibly be ordered towards conscious experience characterized by rational action. This is a deep and complex question that deserves more attention than can be given in this article. Briefly, I take the PVS and anencephaly to be disorders, and a disorder on a substance-view of human beings (assumed for purposes of this paper) is something that impedes or damages what a human being is ordered to. What a human is ordered to does not disappear when the human suffers from a disorder, otherwise it would be no disorder at all (a deep analysis of this line of thought can be found in Thompson 2004). That is to say, if the condition of the PVS or anencephaly totally negated what human beings are ordered to, then the biological individuals with those conditions would not be "human" (i.e. dead by substantial change), an implication I reject. For those who do accept this implication, see section 3.1 for my response.

${ }^{27}$ Shewmon alleges "terminologic confusion" in that the brain dead body is still taken to be a "unity" of some sort, but not a whole, and questions whether there can be unity without wholeness (Shewmon 2011, 39). His own
} 
All organisms have a needy mode of being. Unlike inanimate objects which continue to exist through inertia and without effort, every organism persists only thanks to its own exertions. To preserve themselves, organisms must — and can and do - engage in commerce with the surrounding world. Their constant need for oxygenated air and nutrients is matched by their ability to satisfy that need, by engaging in certain activities, reaching out into the surrounding environment to secure the required sustenance. This is the definitive work of the organism as an organism. It is what an organism "does" and what distinguishes every organism from non-living. And it is what distinguishes a living organism from the dead body that it becomes when it dies (Ibid., 60-61emphasis original).

The President's Council goes on to argue that the capacities for breathing and consciousness signify the presence of three more basic capacities that are fundamental to an organism's vital work:

1. The capacity to be open to the world and receptive to stimuli and signals from the surrounding environment.

2. The capacity to act upon the world so as to obtain selectively what it needs.

3. The capacity to sense the neediness that compels the organism to act so as to obtain what it needs (Ibid., 61).

All three of these capacities are present in a human organism if either a spontaneous, appetitive-

drive to breathe is present or signs of consciousness in terms of awareness or arousal (or both)

are present. ${ }^{28}$ So, the PVS patient is in the class of human organisms; the President's Council

explains:

When a PVS patient tracks light with his or her eyes, recoils in response to pain, swallows liquid placed in the mouth, or goes to sleep and wakes up, such behaviors although they may not indicate self-consciousness - testify to the organism's essential,

criteria mentioned earlier help establish the possibility: an artificially sustained kidney can display "integrative unity" and not be a whole in the sense that a human organism is a whole - it is merely a part of a human organism.

${ }^{28}$ How consciousness is defined is a project in its own right, but what I mean is what the President's Council means when it refers to "openness" to the world in the form of "felt awareness" which is "the inner experience of need" that "does not have to be consciously felt in order to be efficacious" $(2008,62)$. Admittedly, this is pretty ambiguous if not misleading, but the idea seems to be that there is some rudimentary level of consciousness, defined by clinical criteria for responsiveness, manifested in the behavior of bodies that lack awareness but retain some level of arousal (e.g. PVS patients) as opposed to brain-dead bodies that lack both (for more on the distinction between awareness and arousal as it relates to disorders of consciousness and total brain failure, see works by Machado 1999 and Laureys, Boly, and Maquet 2009). To be sure, patients in a coma will lack both awareness and arousal yet may exhibit a drive to breathe; for those who do not exhibit a drive to breathe, clinical tests for total brain failure must have evidence for its cause and rule out confounding factors before a diagnosis of total brain failure can be asserted. Thanks to an anonymous reviewer for raising these issues. 
vital openness to its surrounding world. An organism that behaves in such a way cannot be dead (Ibid., 61).

Likewise, some anencephalic babies exhibit a drive to breathe as they struggle against their fate; some even breastfeed, grasp their caretaker's fingers, and can tell when their mother is holding them (Gray 2016, 79; Shewmon et al. 1989, 1776). The fact that they have a bleak prognosis is no reason to diagnose them as dead any more than one would consider infants with pathetically thin (almost non-existent) cerebral cortices dead (Capron 1987, 6). Hydrancephalic infants may also have bleak prognosis, though one clinician has observed that such individuals are "not only awake and often alert, but show responsiveness to their surroundings in the form of emotional or orienting reactions to environmental events" (Merker 2007, 79). Thus, a (postnatal) human organism dies if both the capacity for consciousness (awareness and arousal) and the capacity for breathing are irreversibly lost (President's Council 2008, 64-65). ${ }^{29}$ Since the condition of total brain failure is adequate for establishing the irreversible loss of both of these capacities, it is adequate to indicate the death of a human organism.

\subsection{How the criteria are connected}

So far, I have argued that the loss of self-movement towards the distinctively human end of rational thought and action is what defines the death of a human organism. Why, then, think that the combined loss of the capacity for consciousness and the capacity to breathe is sign of human death? $?^{30}$ It would seem that these are two different criteria, and they are. Yet the difference is not one of contraries, but one of abstraction. The former criterion is a metaphysical

\footnotetext{
${ }^{29}$ I say "postnatal" because that is the stage of development of when diagnostic criteria for total brain failure applies. This is important, because it sometimes asserted that a brainless and breathless embryo is a counterexample to the criteria (see Gomez-Lobo's personal statement in the White Paper, and Shewmon 2011, 39); an embryo can die by virtue of losing its capacity for cell division (Landry and Zucker 2004). Yet there is no reason why the fundamental work criterion, taken as “the work of self-preservation, achieved through the organism's need-driven commerce with the surrounding world" cannot be operationalized at different stages of development. The criterion is stated in a higher form of generality that permits it to be realized in different ways (contra Shewmon 2009b, 8).

30 Thanks to an anonymous reviewer for raising this question.
} 
description at a high level of abstraction (level 1) whereas the latter criteria are at a lower level of general physiological standards (level 2), for which operational criteria (level 3) and specific tests (level 4) can be specified and deployed to diagnose death. This four-fold ordering of the levels of abstraction was first specified by Capron and Kass (1972) in their influential article delineating what can be legislated in a statutory definition of death; such levels are unavoidable in thinking and communicating about death, since they are a part of our philosophical and clinical interests concerning the determination of death.

Yet we need further argument to show how these criteria are related to total brain failure. One might be tempted to think that defining death in terms of "self-movement towards the distinctively human end of rational thought and action" is just another way of asserting the "higher-brain" rationale for death, albeit one that holds that the loss of the capacity for rational action is sufficient for determining the end of a human organism as a whole. ${ }^{31}$ Yet the "totality" of brain failure is required, because the vital functions found in the "higher" and "lower" parts of the brain regulate and maintain the two distinctive aspects of our lives as rational animals, that is, our capacity for rational action and our capacity to live a biological life, two capacities we bear at a fundamental, or root level as a unified substance. Why think an injured human life remains in the case of a PVS rather than a form of non-human life? We could embrace the odd idea that there is a human organism as a whole lying there in the hospital bed the moment before it loses its capacity for consciousness, and then suddenly goes out of existence and is instantly replaced by a similar looking non-human organism as a whole. ${ }^{32}$ On this view, human death is

\footnotetext{
${ }^{31}$ Again, thanks to the anonymous reviewer for pressing this point. Such a view is rare, but appears in Shewmon's early writing (Shewmon 1985), and the work of Martha Nussbaum who says, "Some types of mental deprivation are so acute that it seems sensible to say that the life there is simply not a human life at all, but a different form of life. Only sentiment leads us to call the person in a persistent vegetative condition, or an anencephalic child, human" (Nussbaum 2006, 187).

${ }^{32}$ Contrast this with my claim that there isn't an organism as a whole there at all after total brain failure.
} 
purely a metaphysical matter, and not something related to death as it occurs in the animal kingdom of biology. Indeed, our death would totally be "beyond biology," something I do not accept. In any event, the oddness of this idea is not sufficient to undermine it as a consistent metaphysical thesis and no amount of empirical evidence is going to determine whether or not this is the case. Yet I accept the biological paradigm and believe Ockham's Razor should lead us to adopt a simpler explanation of what happens to the patient who loses the capacity for conscious awareness in a PVS (assuming this can be reliably diagnosed ${ }^{33}$ ). There is a single organism as a whole there throughout that ends up profoundly injured, because it lacks the ability to activate its ultimate capacities for rational action in the form of conscious thought (Eberl 2011, 15). Couldn't this be said of the brain-dead body too? No, because more is lost in those bodies, specifically the loss of the capacities for consciousness (awareness and arousal) and respiratory effort, which, taken together, signifies the loss of the basic capacity for self-directed action upon the environment to retrieve what is needed in order to continually resist entropic forces and maintain metabolic activity, a capacity which is just as constitutive of our human nature as is the basic capacity for rational action. Therefore, the loss of both of these capacities at their root level in total brain failure signifies the loss of the human organism as a whole, not just the part that activates its mental activity in the "higher" parts of the brain. ${ }^{34}$

\subsection{Answering objections}

\footnotetext{
${ }^{33}$ It is worth noting that higher-brain criteria are even more counterintuitive and harder to empirically discern than our currently accepted neurological criteria. We already have trouble thinking of brain-dead bodies as dead bodies due to their beating hearts and warm skin (Siminoff, Burant, and Youngner 2004). Higher-brain criteria would further discount such life-signs as spontaneous respiration, reaction to painful stimuli, and having a sleepwake cycle. Since the higher-brain criterion effectively hides "the living" from the standard signs of biological life, it is all the more difficult to develop a battery of reliable empirical tests that are capable of clearly indicating that an individual — which is to be identified by a capacity for consciousness — is present. Misdiagnosing the PVS seems especially easy to do in light of recent empirical evidence indicating a preserved awareness in some who were deemed to be in a vegetative state by conventional diagnostic tests (Cruse et al. 2011; Owen et al. 2006).

${ }^{34}$ And therefore, makes human death similar to the death of other members of the animal kingdom.
} 
Three of the most repeated objections to the Council's position are worth considering.

The first comes from Miller and Nair-Collins, who believe that "The strategy of identifying some privileged functions that 'count' (ie [sic], perform 'vital work') as distinct from those that do not 'count' is arbitrary and ad hoc" (Nair-Collins and Miller 2017, 751). To be sure, the maintenance of the blood-air barrier that allows for gas exchange is necessary for human life. "Necessary conditions are necessary conditions," they write, "none are either privileged or discountable" (Ibid.). But surely, this is false. Just because a cause is as necessary as another does not mean that they cannot be distinguished in terms of their source and priority, that is, in terms of whether one is internal and imminent as opposed to external and non-imminent. David Oderberg helps elucidate the concept of immanent causation:

This is a causation that originates with an agent and terminates in that agent for the sake of its self-perfection. It is a kind of teleology, but metaphysically distinctive in what it involves. Immanent causation is not just action for a purpose, but for the agent's own purpose, where "own purpose" means not merely that the agent acts for a purpose it possesses, but that it acts for a purpose it possesses such that the fulfillment of the purpose contributes to the agent's self-perfection. Hence, in immanent causation, the agent is both the cause and the effect of the action, and the cause itself is directed at the effect as a perfective of the agent (2013, 213 emphasis original).

Indeed, Oderberg's idea of immanent causation is a good description of what I mean by "selfmovement." If we could not privilege the imminent causes of self-movement above nonimminent ones, ${ }^{35}$ then we could not even say that living canines are any more alive than robotic dogs, an assumption that is taken to its logical end in the writings of those who espouse abioism (e.g. Jabr 2013) — the idea that life does not really exist. Moreover, we see how the difference between causes internal to a thing and causes external to a thing can matter apart from their

\footnotetext{
${ }^{35}$ Oderberg defines non-imminent causes in terms of "transient causation" as follows: "If A does F to B, and A is not the same [kind] $\mathrm{K}$ as B (for some $\mathrm{K}$ ), and B is not part of A, A does F to B transiently" (Ibid.).
} 
necessity in a functional process. For example, we recognize that a car battery, which cannot hold a charge and is in need of a jump, is "dead" in contrast to one that can turn the starter when prompted by the ignition. While the faulty battery might be able to still complete an electrical circuit and permit the circulation of current so the driver can make a pit stop at the auto parts store, he dare not turn the engine off before he gets there, unless he wants to jump the battery again. ${ }^{36}$ By saying this, I do not mean to draw an analogy between human death and the death of car batteries, but to highlight an important feature of the causal story about a thing, which can in turn provide us with knowledge about the condition of a thing. That is to say, the absence of the immanent causal powers of a thing signifies a problem with the thing, and replacing the immanent powers with non-immanent powers does not reverse the problem, but bypasses and perhaps conceals it.

Second, it is sometimes asserted that the body with total brain failure is like a PVS patient who has diaphragmatic paralysis insofar as both have lost the capacity for consciousness and the capacity for breathing (e.g. Johnson 2016, 107). ${ }^{37}$ Since such a patient is unquestionably alive, so is the patient diagnosed with total brain failure, which is contrary to my argument. But these patients are not alike, because the capacity for respiratory effort is not exhausted by the ability of the diaphragm to move the lungs and is further found in the respiratory control centers of the brainstem. Even the PVS patient with diaphragmatic paralysis is able to sense the need for oxygen and the need to reach out into the environment to get it. ${ }^{38}$ Not so with the patient with

\footnotetext{
${ }^{36}$ Sadly, I know this all too well from experience.

37 Thanks to an anonymous reviewer for raising this objection.

${ }^{38}$ I am using the word "sense" in the way I've already described above, where PVS patients are able to be (partially) aroused though they are not aware. But what about someone in an apneic coma who lacks awareness and arousal? Does this sort of patient satisfy criteria for total brain failure? The short answer is no, more is needed to determine whether the apneic coma is "irreversible" and one might think it is not, since there are cases of people making a recovery out of this state (Agarwal, Singh, and Gupta 2006). Clinical diagnosis must include a battery of tests in order to indicate irreversibility. These are helpfully described by the Council on pages 30-35 of their
} 
total-brain failure. ${ }^{39}$ The capacity for respiratory effort minimally realized by central nervous system signals from the brain stem signifies immanent causal activity unified by the ends of the three basic capacities fundamental to an organism's vital work mentioned above. This effort, as it is normally realized in spontaneous breathing, is not merely a series of events that involves the billowing of the chest with air, as it is with mechanical ventilation — rather, it is a self-motivated activity. Furthermore, the maintenance of the blood-air barrier is not necessarily a sign of an organism's capacity to sense the neediness that compels it to act in order to obtain what it needs, since such an activity can be maintained in a headless body, which is not an organism as a whole at all, but rather an "organism" in name only.

The third objection comes from Shewmon who notes that the President's Council's position depends on the claim that breathing and consciousness are the only two functions that are individually sufficient for human life; if there were another one, their joint absence would not be sufficient for death $(2009 \mathrm{~b}, 10)$. True enough, but what other function does he have in mind? We should remember that the President's Council's position is not advancing conditions merely for life, but rather for the as-a-wholeness of the human organism signified by the vital work of respiratory effort and consciousness. The possibility of there being 'living parts' or a sense of life or vitality as measured by "integrative unity" that can be found in organisms "in name only" has not been eliminated. Respiratory effort and consciousness are named because they unify the ends to which rational animals like ourselves are ultimately directed, that is, living and thinking in the natural world. Likewise, these two functions are empirically detectable in the "higher" and

document, and in the references of this paper made in footnote 29 . Thanks to an anonymous reviewer for raising this question.

${ }^{39}$ This was originally noted by the President's Council, something critics tend to overlook. As the Council puts it in a footnote, "Here, one could say, the CNS [central nervous system] signal to take action is being sent, but it is falling on 'deaf ears.' Alternatively, one may say that the drive to breathe is present but the ability to turn that drive into action is absent" (President's Council on Bioethics 2008, 27). 
"lower" parts of the brain, both of which must be lost if we are to judge the loss of an organism as-a-whole.

The fact that Shewmon, in his focused commentary on the White Paper (2009b), names no other function that would be sufficient wholeness only serves to bolster the Council's position. In his most recent work, commenting on the case of Jahi McMath, he asserts that "some degree of hypothalamic function" is "surely relevant to the "functioning of the organism as a whole'..." (Shewmon 2018, S76). I leave aside questions particular to the McMath case as the debate over the validity of her diagnosis is ongoing. To his comments more generally, "some degree" of hypothalamic-pituitary functioning is "relevant" to the fundamental work of the organism, alright, since it produces hormones sufficient for preventing diabetes insipidus (hormones that have been observed in some bodies diagnosed with total brain failure for decades).$^{40}$ Nevertheless, that some degree of functioning contributes to the fundamental work of the organism does not imply that it indicates the fundamental work of the human organism any more than the heart beat does. The reason not think it is indicative is that it does not exemplify the work of self-preservation, achieved through the organism's need-driven commerce with the surrounding world as indicated by an inner sense of need, an openness to the surrounding environment, and an ability to act upon that environment to satisfy its needs. Endocrine

\footnotetext{
${ }^{40}$ See Halevy and Brody's influential paper for details (Halevy and Brody 1993). The debate over hypothalamic-pituitary functioning is often framed in terms of whether its presence nullifies neurological criteria in light of statutory frameworks that require "all functions of the entire brain" to irreversibly cease (Nair-Collins, Northrup, and Olcese 2014); in places like the United Kingdom where only the death of the brainstem is sufficient to declare death, the functioning is immaterial (Pallis 1999, 94). Assuming a legal context of "entirety" holds, an anonymous reviewer presses the objection that the label "total brain failure" does not represent what I have described here as death, since there could be some patients who are dead who retain some hypothalamic-pituitary function. Here I defer to the Council's comment that "whether or not the word 'total' is justified, the patient diagnosed with total brain failure is in a condition of profound incapacity, diagnostically distinct from all other cases of severe injury" (President's Council on Bioethics 2008, 38 emphasis original). The question for my purposes is whether this condition indicates the end of an organism as a whole, not whether the label adequately describes the condition, which is an interesting, but distinct semantic issue.
} 
functioning simply does not relate to the external environment unlike consciousness (in terms of awareness and arousal) and the drive to breathe. This is the best reason clinicians have to dismiss it as signifying the presence of an organism as a whole in the diagnosis of total brain failure, despite its (potential) responsiveness to biochemical conditions and processes - fussing with the notion of integrative unity is simply inadequate (contra. Bernat 1999, 86). ${ }^{41}$

What about other functions Shewmon has listed? In their commentary on the White Paper, Miller and Truog assert that "fighting infections and wound healing" are indicative of the human organism's fundamental work as an organism (2009a, 189). Additionally, Brugger (2013, 213) names homeostasis and the ability to take in nutrition and hydration as indicating the threefold criteria. The gestation of a fetus certainly seems to be another good candidate (Johnson 2016, 106). ${ }^{42}$ Yet all these functions depend on a capacity to act upon the surrounding environment that is more fundamental to the resistance of entropic forces than any of these: the capacity to breathe, which is the capacity to sense what is needed and 'reach out' into the environment and attain what it needs (oxygen) and to 'push out' into the environment what is toxic (waste). ${ }^{43}$ The reason the need-driven exchange of gasses is so important relates to

\footnotetext{
${ }^{41}$ Of course, the degree of responsiveness the hypothalamus is capable of should matter in tests for the irreversibility of total brain failure, since, according Widjicks, "[s]timulation of the posterior hypothalamus" causes arousal (Wijdicks 2010,52). We should also be sensitive to detections of auditory evoked potentials, which may indicate some remaining brainstem functioning (for more commentary on the significance of this phenomena, see Laureys 2005, 904; Facco and Machado 2004). How these tests should proceed is a beyond the scope my inquiry.

${ }^{42} \mathrm{An}$ anonymous reviewer also includes the assimilation of nutrients in the gut, the excretion of soluble wastes by the kidneys, and the insoluble wastes by the intestines as functions that equally to 'reach out' into the environment and attain what it needs (nutrients) or 'push out' into the environment what is toxic (waste). Why is the need-driven exchange of gases the only kind of exchange that matters for the ontological status of "organism"? The answer is found in the fact that oxygen is a fundamental element of mammalian life, the loss of which is sensed before the loss of the ability to take in nutrients and the ability to expel soluble and insoluble waste. There being no ability to sense this loss and no ability to remedy it is as good of a sign of death as any. After all, the entropyresisting functions will not continue for long without respiratory effort whereas they can persist much longer without taking in nutrition.

${ }^{43}$ An anonymous reviewer raises the issue of their being an isolated gag reflex in a human apparently lacking respiratory drive and consciousness, which would in standard practice be taken as a sign of life. Does my view, then, generate a false positive? I think not, because a gag reflex provides evidence that the capacity for consciousness in terms of arousal has not been lost.
} 
oxygen's fundamental role in mammalian life insofar as it removes toxins from the body, and drives our metabolic functioning, converting glucose into energy. Even if the first-order capacity to breathe is blocked by an injury, the second-order drive of respiratory effort remains. As the President's Council says, "This drive is the organism's own impulse, exercised on its own behalf, and indispensable to its continued existence" (President's Council on Bioethics 2008, 62). ${ }^{44}$ This capacity is entirely lost in total brain failure. ${ }^{45}$ Thus, the functions critics appeal to are definitely functions of a living thing, alright (certainly not that of a rotting corpse), but they need not only be functions of an organism as a whole. Rather, they can just as well be the coordinated activity of a living part of an organism, a part that could just as easily be identified with an artificially sustained headless human body. ${ }^{46}$ This should not be altogether surprising (though it is fascinating), since it is just this sort of entity that can supply healthy vital organs for transplant.

\section{Conclusion}

\footnotetext{
${ }^{44}$ In their effort to debunk the President's Council's Position Two, Shah and Miller assert that fetuses "do not have a drive to breathe" apparently because they "take in amniotic fluid in order to obtain oxygen" (2010, 550). An anonymous reviewer points out that this is false; fetuses take in oxygen not from the amniotic fluid, but blood flow from the umbilical cord. Nonetheless, does this mean that viable fetuses lack the drive to breathe altogether? Certainly not, otherwise we would fail to breathe when we are born (the process of which is well-described in Hillman, Kallapur, and Jobe 2012). Perhaps they think the drive to breath appears only when one is outside the womb. That too is false, because a mature ( 8 month) fetus can breathe inside the womb as the following report indicates:

Dr. Liley relates the experience of a doctor who injected an air bubble into an unborn baby's (eight months) amniotic sac in an attempt to locate the placenta on X-ray. It so happened that the air bubble cover the unborn baby's face. The moment the unborn child had air to inhale, his vocal cords became operative and his crying became audible to all present, including the physician and technical help. The mother telephoned the doctor later to report that whenever she lay down to sleep, the air bubble got over the unborn baby's face and he was crying so loudly he was keeping both her and her husband awake (Horan 1971 quoted in Schwarz 1990, 6).

45 An anonymous reviewer objects that the relevant aspect of a human organism's respiratory effort is found in the capacity for gasses to cross the alveolar membrane of the lungs, and not the effort to take in air to fill the lungs. I respond that this cannot be the case, because such a capacity can be preserved in lungs perfused ex vivo (Nelson et al. 2015). Such an activity may be the fundamental work of lungs, alright, but vital human organs do not add up to a human organism as a whole.

${ }^{46}$ Some empirical evidence to suggest that this is the case is found in an experiment where researchers decapitated a pregnant sheep, sustained the headless body by artificial means, and subsequently delivered a healthy lamb (Steinberg and Hersch 1995). To be sure, as an anonymous reviewer rightly points out, the experiment did not demonstrate that a fetus can successfully gestate and develop in a decapitated mother. However, one never knows what our medical technology is capable of sustaining with the right care in the right circumstances where a surrogate, who could attest to the mother's pro-life convictions, would allow for something like this to be tried.
} 
While it is true that the biophilosophical justification for the idea that total brain failure is death has been under assault for the last 40 years, and has undergone revision, it can be given a strong defense. As we have seen, the defense of this justification depends on two claims: (1) that what dies in human death is a human organism, not merely a psychological entity distinct from it; and (2) that total brain failure signifies the end of the human organism as a whole. Defenders of brain death have typically assumed without argument that the first claim is true and argue for the second by defending the "integrative unity" rationale. Yet the integrative unity rationale has fallen on hard times. I have, nonetheless, provided reasons for why we should think of ourselves as organisms, and why the "fundamental work" rationale put forward by the 2008 President's Council is better than the integrative unity rationale despite persistent objections to it. None of this this is to say that our current tests or diagnosing practices for total brain failure are perfect. At the very least, the tragic case of Jahi McMath gives us a reason to scrutinize and refine our tests for total brain failure (Magnus, Wilfond, and Caplan 2014). ${ }^{47}$ But, as I see it, better arguments are needed in order to deny that total brain failure cannot indicate the end of a human organism as a self-moving whole. ${ }^{48}$

${ }^{47}$ Shewmon testified under oath that McMath satisfied the tests in December, 2013, but no longer did as of October, 2014.

${ }^{48}$ I thank Dr. Burke Dial for helping me better understand the clinical differences between anencephaly, hydranencephaly, the PVS, and total brain failure. I also thank two very tough, but helpful anonymous reviewers for making this paper much better than it originally was. 


\section{Works Cited}

Agarwal, R, N Singh, and D Gupta. 2006. "Is the Patient Brain-dead?" Emergency Medicine Journal: EMJ 23 (1): e5. https://doi.org/10.1136/emj.2004.019182.

Bailey, Andrew M. 2016. "You Are an Animal." Res Philosophica 93 (1): 205-218.

Baker, Lynne Rudder. 2000. Persons and Bodies: A Constitution View. Cambridge; New York: Cambridge University Press. 2008. "Response to Eric Olson." Abstracta 3 (3): 43-45.

Bernat, J. L., C. M. Culver, and B. Gert. 1981. "On the Definition and Criterion of Death." Annals of Internal Medicine 94 (3): 389-94.

Bernat, James L. 1999. "Refinements in the Definition and Criterion for Death." In The Definition of Death: Contemporary Controversies, edited by Stuart J. Youngner, Robert M. Arnold, and Renie Schapiro, 83-92. Baltimore, MD: John Hopkins University Press. https://ci.nii.ac.jp/naid/10015426200/.

—. 2014. "Whither Brain Death?" The American Journal of Bioethics 14 (8): 3-8. https://doi.org/10.1080/15265161.2014.925153.

Blatti, Stephan. 2014. “Animalism.” In The Stanford Encyclopedia of Philosophy, edited by Edward N. Zalta, Summer 2014. http://plato.stanford.edu/archives/sum2014/entries/animalism/.

Bouchard, Frédéric, and Philippe Huneman. 2013. From Groups to Individuals: Evolution and Emerging Individuality. Cambridge: MIT Press.

Braine, David. 1992. The Human Person: Animal and Spirit. South Bend, Ind: University of Notre Dame Press.

Brandt, Stephan A., and Heinz Angstwurm. 2018. "The Relevance of Irreversible Loss of Brain Function as a Reliable Sign of Death.” Deutsches Ärzteblatt International 115 (41): 67581. https://doi.org/10.3238/arztebl.2018.0675.

Brugger, E. Christian. 2013. "D. Alan Shewmon and the PCBE's White Paper on Brain Death: Are Brain-Dead Patients Dead?” Journal of Medicine \& Philosophy 38 (2): 205-18.

Campbell, Tim, and Jeff McMahan. 2010. "Animalism and the Varieties of Conjoined Twinning." Theoretical Medicine and Bioethics 31 (4): 285-301.

Capron, Alexander Morgan. 1987. "Anencephalic Donors: Separate the Dead from the Dying." The Hastings Center Report 17 (1): 5-9. https://doi.org/10.2307/3562433.

Capron, Alexander Morgan, and Leon R. Kass. 1972. "Statutory Definition of the Standards for Determining Human Death: An Appraisal and a Proposal." University of Pennsylvania Law Review 121: 87.

Charo, R. Alta. 2001. "Every Cell Is Sacred: The Logical Consequences of the Argument from Potential in an Age of Cloning." In Cloning and the Future of Human Embryo Research, edited by Paul Lauritzen, 82-113. New York: Oxford University Press.

Condic, Maureen L. 2016. "Determination of Death: A Scientific Perspective on Biological Integration.” Journal of Medicine and Philosophy 41 (3): 257-78. https://doi.org/10.1093/jmp/jhw004.

Cruse, Damian, Srivas Chennu, Camille Chatelle, Tristan A Bekinschtein, Davinia FernándezEspejo, John D Pickard, Steven Laureys, and Adrian M Owen. 2011. "Bedside Detection of Awareness in the Vegetative State: A Cohort Study." The Lancet 378 (9809): 208894. https://doi.org/10.1016/S0140-6736(11)61224-5.

Dennett, Daniel C. 1978. “Where Am I?” In Brainstorms. MIT Press. 
DiSilvestro, Russell. 2010. Human Capacities and Moral Status. Vol. 108. Philosophy and Medicine. Dordrecht; Heidelberg; London; New York: Springer.

Eberl, Jason T. 2011. "The Unactualized Potential of PVS Patients." APA Newsletter 11 (1): 1418.

Facco, Enrico, and Calixto Machado. 2004. "Evoked Potentials in the Diagnosis of Brain Death." Advances in Experimental Medicine and Biology 550: 175-87.

Flanagan, Owen J. 1991. The Science of the Mind. 2nd ed. Cambridge, MA: MIT Press.

George, Robert P., and Christopher Tollefsen. 2008. Embryo: A Defense of Human Life. 1st ed. New York: Doubleday.

Gervais, Karen G. 2014. "The Social Construction of Death, Biological Plausibility, and the Brain Death Criterion." The American Journal of Bioethics 14 (8): 33-34. https://doi.org/10.1080/15265161.2014.925162.

Gervais, Karen Grandstrand. 1986. Redefining Death. New Haven: Yale University Press.

Gray, Sarah. 2016. A Life Everlasting: The Extraordinary Story of One Boy's Gift to Medical Science. 1 edition. HarperOne.

Green, Michael B., and Daniel Wikler. 1980. "Brain Death and Personal Identity." Philosophy \& Public Affairs 9 (2): 105-33.

Halevy, A, and B Brody. 1993. "Brain Death: Reconciling Definitions, Criteria, and Tests." Annals Of Internal Medicine 119 (6): 519-25.

Hershenov, David B. 2005. "Persons as Proper Parts of Organisms." Theoria 71 (1): 29-37. https://doi.org/10.1111/j.1755-2567.2005.tb01003.x.

Hillman, Noah H., Suhas G. Kallapur, and Alan H. Jobe. 2012. "Physiology of Transition from Intrauterine to Extrauterine Life." Clinics in Perinatology 39 (4): 769-83. https://doi.org/10.1016/j.clp.2012.09.009.

Horan, Dennis J. 1971. "Motion and Brief, Amicus Curiae of Certain Physicians, Professors and Fellows of the American College of Obstetrics and Gynecology in Support of Appellees."

Inwagen, Peter van. 2007. "A Materialist Ontology of the Human Person." In Persons: Human and Divine, edited by Peter van Inwagen and Dean Zimmerman, 199-215. Oxford; New York: Oxford University Press.

Jabr, Ferris. 2013. "Why Life Does Not Really Exist." Brainwaves, Scientific American Blog Network. 2013. http://blogs.scientificamerican.com/brainwaves/2013/12/02/why-lifedoes-not-really-exist/.

Johnson, L. Syd M. 2016. "The Case for Reasonable Accommodation of Conscientious Objections to Declarations of Brain Death.” Journal of Bioethical Inquiry 13 (1): 105-15. https://doi.org/10.1007/s11673-015-9683-z.

Kaufman, M. H. 2004. "The Embryology of Conjoined Twins.” Childs Nervous System 20 (8-9): 508-25. https://doi.org/10.1007/s00381-004-0985-4.

Khushf, George. 2010. "A Matter of Respect: A Defense of the Dead Donor Rule and of a 'Whole-Brain' Criterion for Determination of Death." Journal of Medicine and Philosophy 35 (3): 330-64. https://doi.org/10.1093/jmp/jhq023.

Landry, Donald W., and Howard A. Zucker. 2004. "Embryonic Death and the Creation of Human Embryonic Stem Cells.” Journal of Clinical Investigation 114 (9): 1184-86. https://doi.org/10.1172/JCI23065.

Laureys, S, M Boly, and P Maquet. 2009. “Coma.” Edited by Larry R Squire. Encyclopedia of Neuroscience. London: Elsevier. 
Laureys, Steven. 2005. "Death, Unconsciousness and the Brain." Nature Reviews Neuroscience 6 (11): 899-909. https://doi.org/10.1038/nrn1789.

Lee, Patrick, and Robert P. George. 2008. Body-Self Dualism in Contemporary Ethics and Politics. New York, NY: Cambridge University Press.

Liao, S. Matthew. 2006. "The Organism View Defended." The Monist 89 (3): 334-50.

LiPuma, Samuel, and Joseph P. DeMarco. 2014. "A Functionalist View of Brain Death." The American Journal of Bioethics 14 (8): 19-20. https://doi.org/10.1080/15265161.2014.925159.

Lizza, John P. 2006. Persons, Humanity, and the Definition of Death. Baltimore, MD: Johns Hopkins University Press.

- 2009. "Commentary on 'The Incoherence of Determining Death by Neurological Criteria." Kennedy Institute of Ethics Journal 19 (4): 393-95. 2018. "Defining Death: Beyond Biology." Diametros 55 (55): 1-19.

Machado, Calixto. 1999. "Consciousness as a Definition of Death: Its Appeal and Complexity." Clinical Electroencephalography 30 (4): 156-64. https://doi.org/10.1177/155005949903000408.

Magnus, David C., Benjamin S. Wilfond, and Arthur L. Caplan. 2014. "Accepting Brain Death." The New England Journal of Medicine 370 (10): 891-94. https://doi.org/10.1056/NEJMp1400930.

Marsh, Henry. 2014. Do No Harm: Stories of Life, Death, and Brain Surgery. New York: Thomas Dunne Books.

McMahan, Jeff. 2002. The Ethics of Killing: Problems at the Margins of Life. Oxford Ethics Series. New York: Oxford University Press. . 2009. "Death, Brain Death, and Persistent Vegetative State." In A Companion to Bioethics, edited by Helga Kuhse and Peter Singer, Second Edition, 286-98. Blackwell Companions to Philosophy. Malden: Wiley-Blackwell.

Meilaender, Gilbert. 1993. "Terra Es Animata: On Having a Life.” Hastings Center Report 23 (4): 25-32. https://doi.org/10.2307/3562587.

Merker, Bjorn. 2007. "Consciousness without a Cerebral Cortex: A Challenge for Neuroscience and Medicine." Behavioral and Brain Sciences, no. 1: 63.

Miller, Franklin G., and Robert D. Truog. 2009a. "The Incoherence of Determining Death by Neurological Criteria: A Commentary on Controversies in the Determination of Death, a White Paper by the President's Council on Bioethics." Kennedy Institute of Ethics Journal 19 (2): 185-93.

—. 2009b. "The Incoherence of Determining Death by Neurological Criteria: Reply to John Lizza." Kennedy Institute of Ethics Journal 19 (4): 397-399. . 2012. Death, Dying, and Organ Transplantation: Reconstructing Medical Ethics at the End of Life. Oxford; New York: Oxford University Press.

Moreland, J. P., and Scott B. Rae. 2000. Body \& Soul: Human Nature \& the Crisis in Ethics. Downers Grove, IL: InterVarsity Press.

Moschella, Melissa. 2016a. "Integrated but Not Whole? Applying an Ontological Account of Human Organismal Unity to the Brain Death Debate." Bioethics 30 (6): n/a-n/a. . 2016b. "Deconstructing the Brain Disconnection-Brain Death Analogy and Clarifying the Rationale for the Neurological Criterion of Death." Journal of Medicine and Philosophy 41 (3): 279-99. https://doi.org/10.1093/jmp/jhw006. 
- 2017. "Complexity of Defining Death: Organismal Death Does Not Mean the Cessation of All Biological Life." Journal of Medical Ethics 43 (11): 754-55. https://doi.org/10.1136/medethics-2017-104363.

Nair-Collins, Michael. 2018. “A Biological Theory of Death: Characterization, Justification, and Implications." Diametros 55 (55): 27-43.

Nair-Collins, Michael, and Franklin G. Miller. 2017. "Do the 'Brain Dead' Merely Appear to Be Alive?” Journal of Medical Ethics, August, medethics-2016-103867. https://doi.org/10.1136/medethics-2016-103867.

Nair-Collins, Michael, Jesse Northrup, and James Olcese. 2014. "Hypothalamic-Pituitary Function in Brain Death: A Review." Journal of Intensive Care Medicine 31 (1): 41-50. https://doi.org/10.1177/0885066614527410.

Napier, Stephen. 2011. "Out of the Frying Pan and into the Fire." The American Journal of Bioethics 11 (8): 60-61. https://doi.org/10.1080/15265161.2011.583329.

Nelson, Kevin, Christopher Bobba, Emre Eren, Tyler Spata, Malak Tadres, Don Hayes, Sylvester M. Black, Samir Ghadiali, and Bryan A. Whitson. 2015. "Method of Isolated Ex Vivo Lung Perfusion in a Rat Model: Lessons Learned from Developing a Rat EVLP Program." Journal of Visualized Experiments : JoVE, no. 96 (February). https://doi.org/10.3791/52309.

Nguyen, Doyen. 2018. The New Definitions of Death for Organ Donation: A Multidisciplinary Analysis from the Perspective of Christian Ethics. Bern: Peter Lang.

Nicholson, Daniel J. 2013. "Organisms $\neq$ Machines." Studies in History and Philosophy of Science Part C: Studies in History and Philosophy of Biological and Biomedical Sciences 44 (4, Part B): 669-78. https://doi.org/10.1016/j.shpsc.2013.05.014.

- 2014. "The Machine Conception of the Organism in Development and Evolution: A Critical Analysis." Studies in History and Philosophy of Science Part C: Studies in History and Philosophy of Biological and Biomedical Sciences 48, Part B (December): 162-74. https://doi.org/10.1016/j.shpsc.2014.08.003.

Nussbaum, Martha C. 2006. Frontiers of Justice: Disability, Nationality, Species Membership. Cambridge, MA: Harvard University Press.

Oderberg, David S. 2013. "Synthetic Life and the Bruteness of Causation." In Aristotle on Method and Metaphysics, edited by Edward Feser, 206-35. Palgrave Macmillan.

Olson, Eric T. 1997. The Human Animal: Personal Identity without Psychology. New York: Oxford University Press. . 2004. "Animalism and the Corpse Problem.” Australasian Journal of Philosophy 82 (2): 265-74. . 2007. What Are We? A Study in Personal Ontology. Oxford; New York: Oxford University Press. . 2015. "Personal Identity." In The Stanford Encyclopedia of Philosophy, edited by Edward N. Zalta, Spring 2016. http://plato.stanford.edu/archives/spr2016/entries/identitypersonal/.

- 2016. "The Role of the Brainstem in Personal Identity." In Animals: New Essays, edited by Andreas Blank. Philosophia.

Owen, Adrian M., Martin R. Coleman, Melanie Boly, Matthew H. Davis, Steven Laureys, and John D. Pickard. 2006. "Detecting Awareness in the Vegetative State." Science 313 (5792): 1402-1402. https://doi.org/10.1126/science.1130197. 
Pallis, Chris. 1999. “On the Brainstem Criterion of Death.” In The Definition of Death:

Contemporary Controversies, edited by Stuart J. Youngner, Robert M. Arnold, and Renie Schapiro, 93-100. Baltimore, MD: John Hopkins University Press. https://ci.nii.ac.jp/naid/10015426200/.

Parfit, Derek. 1984. Reasons and Persons. Oxford University Press.

President's Commission for the Study of Ethical Problems in Medicine and Biomedical and Behavioral Research. 1981. Defining Death: A Report on the Medical, Legal and Ethical Issues in the Determination of Death. Washington, D.C.: The Commission : For sale by the Supt. of Docs., U.S. G.P.O.

President's Council on Bioethics. 2008. Controversies in the Determination of Death: A White Paper of the President's Council on Bioethics. Washington, D.C.: President's Council on Bioethics.

Repertinger, Susan, William P. Fitzgibbons, Mathew F. Omojola, and Roger A. Brumback. 2006. "Long Survival Following Bacterial Meningitis-Associated Brain Destruction." Journal of Child Neurology 21 (7): 591-95. https://doi.org/10.1177/08830738060210070401.

Rosenkrantz, Gary S. 2015. "Life and Death.” The Monist 98 (3): 303-17. https://doi.org/10.1093/monist/onv011.

Schrödinger, Erwin. 1992. What Is Life? With Mind and Matter and Autobiographical Sketches. Cambridge University Press.

Schwarz, Stephen D. 1990. The Moral Question of Abortion. First edition. Chicago: Loyola University Press.

Shah, Seema K., and Franklin G. Miller. 2010. "Can We Handle the Truth? Legal Fictions in the Determination of Death." American Journal of Law \& Medicine 36 (4): 540-85. https://doi.org/10.1177/009885881003600402.

Shewmon, D. Alan. 1985. "The Metaphysics of Brain Death, Persistent Vegetative State and Dementia." The Thomist 49 (1): 24. . 1998. "Chronic 'Brain Death' Meta-Analysis and Conceptual Consequences." Neurology 51 (6): 1538-45. https://doi.org/10.1212/WNL.51.6.1538.

- 2001. "The Brain and Somatic Integration: Insights into the Standard Biological Rationale for Equating ‘brain Death' with Death.” The Journal of Medicine and Philosophy, no. 5: 457.

— 2007. "Mental Disconnect: 'Physiological Decapitation' as a Heuristic for Understanding 'Brain Death.”' In The Signs of Death, edited by Marcelo Sánchez Sorondo, 292-333. Pontificiae Academiae Scientiarvm Scripta Varia 110. Vatican City: The Pontifical Academy of Sciences. . 2009a. "On Conscious Non-Organisms, Unconscious Persons, and Bisected PersonOrganisms." American Philosophical Association Newsletter 9 (1): 14-18. . 2009b. "Brain Death: Can It Be Resuscitated?" Issues in Law \& Medicine 25 (July): 3. . 2010. "Constructing the Death Elephant: A Synthetic Paradigm Shift for the Definition, Criteria, and Tests for Death." Journal of Medicine and Philosophy 35 (3): 256-98. https://doi.org/10.1093/jmp/jhq022. . 2011. "Controversies Surrounding Brain Death." In The Ethics of Organ Transplantation, edited by Steven J. Jensen, 21-42. Washington, D.C.: Catholic University of America Press. 
https://login.pallas2.tcl.sc.edu/login?url=http://search.ebscohost.com/login.aspx?direct=tr ue $\& d b=$ nlebk \&AN=943099\&site $=$ ehost-live.

2012. "You Only Die Once: A Reply to Nicholas Tonti-Filippini." Communio 39 (3): $422-94$.

_ 2018. "The Case of Jahi McMath: A Neurologist's View." Hastings Center Report 48 (S4): S74-76. https://doi.org/10.1002/hast.962.

Shewmon, D., A.M. Capron, W.J. Peacock, and B.L. Schulman. 1989. "The Use of Anencephalic Infants as Organ Sources: A Critique.” JAMA 261 (12): 1773-81. https://doi.org/10.1001/jama.1989.03420120111036.

Shewmon, DA. 1997. "Recovery from 'Brain Death': A Neurologist's Apologia." The Linacre Quarterly 64 (1): 30-96.

Siminoff, Laura A., Christopher Burant, and Stuart J. Youngner. 2004. "Death and Organ Procurement: Public Beliefs and Attitudes." Social Science \& Medicine 59 (11): 232534. https://doi.org/10.1016/j.socscimed.2004.03.029.

Singer, Peter, and Karen Dawson. 1988. "IVF Technology and the Argument from Potential." Philosophy and Public Affairs 17 (2): 87-104.

Smith, Barry, and Berit Brogaard. 2003. "Sixteen Days." Journal of Medicine and Philosophy 28 (1): 45-78.

Steinberg, A, and M Hersch. 1995. "Decapitation of a Pregnant Sheep: A Contribution to the Brain Death Controversy." Transplantation Proceedings 27 (2): 1886-87.

Swinburne, Richard. 1997. The Evolution of the Soul. Revised. New York: Oxford University Press.

Thompson, Michael. 2004. "Apprehending Human Form.” In Modern Moral Philosophy, edited by Anthony O'Hear, 47-74. Cambridge: Cambridge University Press. http://www.cambridge.org/uk/catalogue/catalogue. asp?isbn=9780521603263.

Thomson, Judith Jarvis. 1971. “A Defense of Abortion.” Philosophy \& Public Affairs 1 (1): 4766.

Toner, Patrick. 2011. "Hylemorphic Animalism.” Philosophical Studies: An International Journal for Philosophy in the Analytic Tradition 155 (1): 65-81.

Van Inwagen, Peter. 1990. Material Beings. Ithaca, N.Y.: Cornell University Press.

Veatch, Robert M. 1975. "The Whole-Brain-Oriented Concept of Death: An Outmoded Philosophical Formulation." Journal of Thanatology 3 (1): 13-30.

—. 2015. "Killing by Organ Procurement: Brain-Based Death and Legal Fictions." Journal of Medicine and Philosophy 40 (3): 289-311.

Wijdicks, Eelco F. M. 2010. “The Bare Essentials: Coma." Practical Neurology 10 (1): 51-60. https://doi.org/10.1136/jnnp.2009.200097. 